\title{
A Study on the Function of Academic Activities to Improve Academic Environment - Illustrated by the Academic Week of Dalian University of Technology
}

\author{
Dongyang Wang, Yan Xiao, and Jie Tao
}

\begin{abstract}
By means of practical case studies and site visits, this paper uses the Academic Week held in School of Architecture and Fine Art of Dalian University of Technology as the research objects and explores the organizational pattern of student-arranged activities in universities. The results demonstrate that during the activity, diversified contents and forms as well as academic platforms composed of multiple subjects can stimulate students' academic competence, thereby improving the academic environment. Moreover, the paper has also revealed the problems in the activity and provided relevant suggestions in this regard. This aside, it provides a new method to explore research-oriented instruction and it also enhances the overall academic ambience, and the arrangement of this event has greatly promoted the research and academic level of the school, effectively improving its reputation in the field and sector.
\end{abstract}

Index Terms - Academic week, academic activities, academic environment, teaching research.

\section{INTRODUCTION}

A superior academic environment lays a solid foundation to ensure a higher academic level of a university, thereby stimulating students' innovation and research ability. In order to implement the principles of Overall Scheme to Integrate and Promote the Construction of World-class Universities and Disciplines initiated by the CPC and the State Council, Dalian University of Technology will, with its purpose of cultivating talented personnel, continue to tread on the road characteristic of connotative development, therefore enhancing the effectiveness of the theories. The Academic Week held in the School of Architecture and Fine Art may well be a productive practise and exploration, because the academic activity, within one week [1], presented integrated subjects, rich contents and various forms[2], generating desirable academic environment and improving students' intellectual accomplishment [3]. (see Fig. 1)

The School of Architecture and Fine Art, in the November of 2016, initially held the activity of Academic Week, with dozens of famous experts presented. As in Fig. 2, a variety of academic activities and interactions between teachers and students brought praises and attentions from relevant fields. The first event laid solid foundation for the continuation of

Manuscript received May 30, 2018; revised November 23, 2018. This work was supported in part by "Dalian University of Technology Graduate Fund" under Grant Jg2016043.

The authors are with the School of Architecture and Fine Art, Dalian University of Technology, China (e-mail: dywang@dlut.edu.cn, xiaoyan@dlut.edu.cn, taojie@dlut.edu.cn). the activity with superior effectiveness. The second activity was launched in the October of 2017 , so as to further the academic ambience and exchanges, and to improve the popularity of the university. The school invited relevant professionals, in joint efforts, to explore the origin of architecture and arts, to carry forward the spirit combined with critical thinking and technology, and to review the duty and role of contemporary designers. During the event, a series of 18 lectures was arranged by a group, led by Toyo Ito, of illustrious architects and critics of architecture, inside and outside the country.

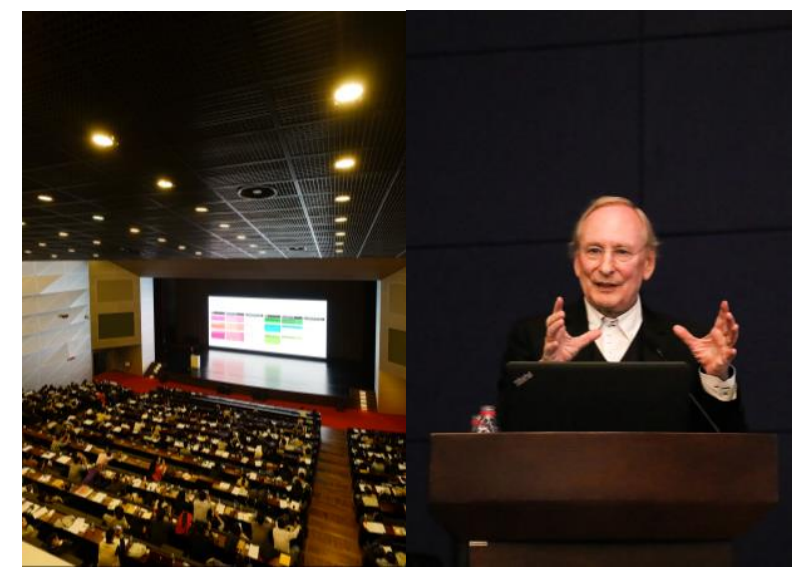

Fig. 1. The second academic week held by School of Architecture and Fine Art of Dalian University of Technology.

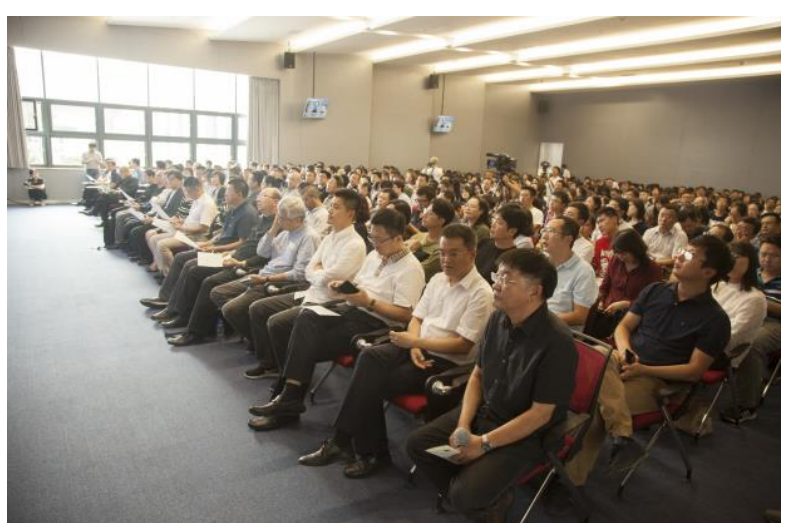

Fig. 2. The lecture participation of teachers and students.

The activity had been held consecutively for two times. Compared with the previous Academic Week, the scale and quality of the activity this time has been proved better. During the event, first, the instruction methods and research awareness of teachers has been enhanced with the integration of teaching and studying [4]; second, students' interest towards disciplines has been arousing, thus improving their learning ability[5]; third, the cooperation between teachers 
and administrators has been achieved, so as to ensure the orderly arrangements and smooth processes of the activity; forth, teachers and students have endeavored to integrate practise into instruction. All in all, the activity has not only enhanced the overall academic ambience but attained an innovation exploration concerning the mechanism of research-oriented teaching.

All faculty and students experienced, through these two successfully consecutive events, the spirit to advocate science of experts and excellent architects, the enthusiasm and quality of predecessors to pursue rigorous scholarship and superior works, which stimulate teachers and students to renovate the academic environment. The arrangement of this event has greatly promoted the research and academic level of the school, effectively improving its reputation in the field and sector.

\section{THE ORGANIZATIONAL PATtERN OF THE ACTIVITY}

\section{A. The Organizational Contents Composed of Multiple Disciplines}

Through the integration of multiple disciplines, e.g. architecture, ekistics and arts, and the advantageous disciplines of Dalian University of Technology, e.g. logic, engineering, technology and liberal arts, the Academic Week of School of Architecture and Fine Art covered various scopes like architecture, ekistics, designs and fine arts. As in Fig. 3, the event adopted several integrated perspectives [6], attracted talented personnel from dozens of disciplines, e.g. ekistics, architecture, landscape science, configuration and visual communication, and thoroughly presented the ideas and exploration regarding the essence of construction and the spirit of arts in China at the present moment.

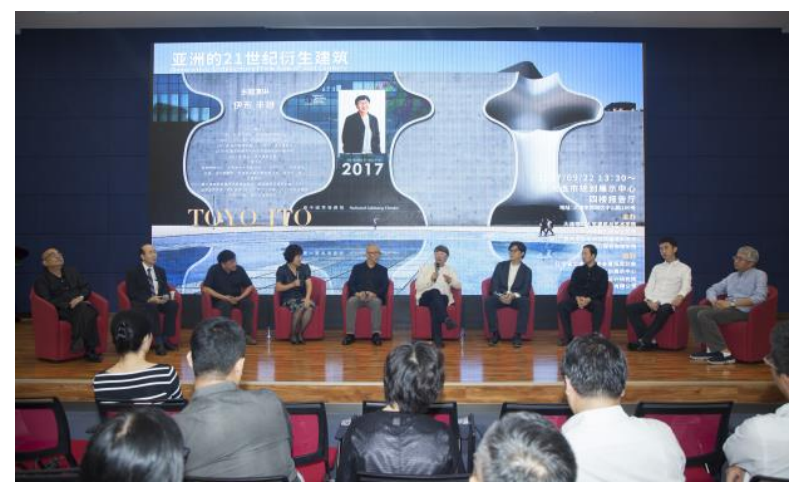

Fig. 3. Academic salon held in academic week.

The major discussion of the activity revolved around the multidisciplinary cross. During the event the platform for academic researches was formed so as to enhance relevant discussions, to lead students from various departments to further their communication and discussion, thereby stimulating them to provide sophisticated ideas. Apart from expanding their academic horizon and communicative room, the event, through respecting students' individual features and their majors, grades and employment objectives, organized targeted activities in all forms, e.g. the workshops specially designed for sophomores, the innovative academic salon set for juniors, and academic lectures for postgraduates regarding the way to do academic researches. All these were initiated with aims, combining multiple disciplines, thereby forming an open and interactive academic environment to foster students' ability of innovative thinking [7]. (see Fig. 4 and Fig. 5)

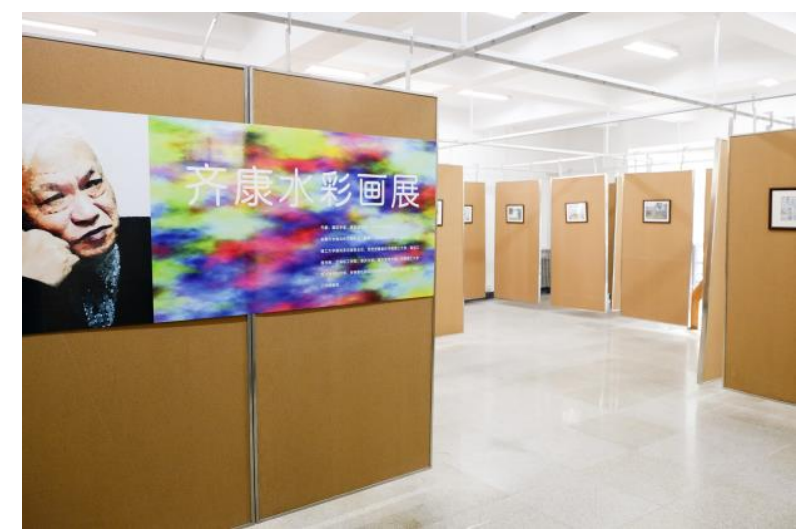

Fig. 4. Exhibition of watercolor paintings.

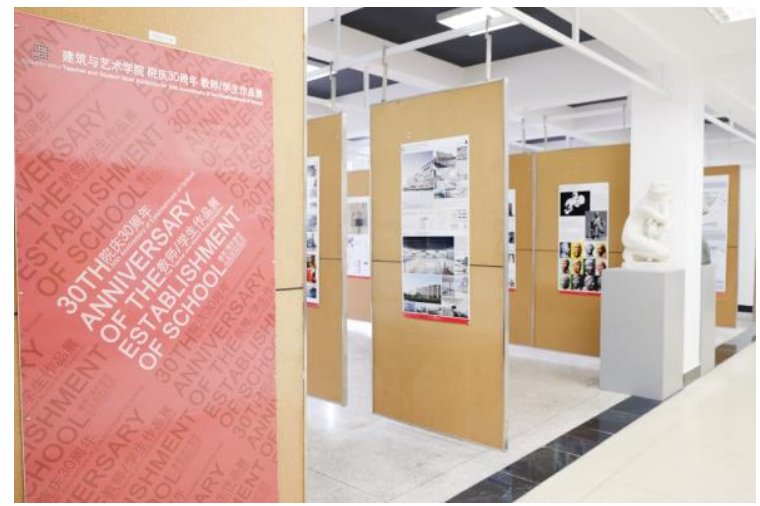

Fig. 5. Design works exhibition of students.

\section{B. Diversified Organizational Forms of the Academic} Event

Regarding the forms of the Academic Week, the school designed a series of activities, e.g. lectures presented by well-known professors, academic salons, designing workshops, scientific guidance, and the presentation of academic achievements by teachers and students. They were highly diversified with concrete contents, so as to cultivate a superior academic environment.

Meanwhile, the school arranged various salons by inviting a group of guiding tutors of wining the Apprentice-themed competition at national level as well as relevant students in charge of the program to share their experience, in order to set a good example for our students to participate in the contest. This aside, excellent postgraduates offered their salons to share their experiences about writing scientific papers and standards in this regard.

Activity one: "Courses of Famous Professor". The school invited well-known professors specializing in the subject of architecture, as well as urban and rural planning, both at home and abroad to carry out splendid academic lectures and they made cordial exchanges with the teachers and students of the school. The famous professors from Tsinghua University, Tongji University, Huazhong University of Science and Technology and Zhejiang University etc. communicated with the teachers and students majoring in building so as to explore and think about the essence and development trend of construction on the theme of "the 
development and changes of architecture under the historical background" by taking into account their respective fields of research based on their profound teaching background.

Mr. Toyo Ito, a well-known Japanese architect who was ever awarded The Pritzker Architecture Prize which is known as the "Nobel prize for architecture", and Mr. Gabor, a famous German architect, as well as other famous architects, elaborated the design process of the "harmonious symbiosis with the natural environment, the dialogue and communication with the original building, and the effect of the different relations with itself and the outside world" through the exhibition of the classic cases of the international office and the strategy of the Asia Pacific development. These excellent techniques are like shining pearls sending forth the light of thought in the "Art Week" of the construction technology, opening a new window of design for the teachers and students.

As in Fig. 6, Mr. Li Hu, Mr. Dong Gong and Mr. Liu Yichun, who are respectively founder of the OPEN Architecture, the Vector Architects, and the Deshaus, are the outstanding representatives of young architects in our country. They inherit and carry forward the spirit of Chinese traditional craftsmen with their own design practice and interpret the due roles and responsibilities of contemporary architects.

Activity two: "Design Workshop". It serves as one of the most distinctive highlights of the "Academic Week of Building Art", and it can improve students' fast design and practice ability through joint teaching in a short period of time. This "Academic Week of Building Art" also invited Professor Gu Daqing of the Chinese University of Hong Kong, and organized the sophomore undergraduate students to conduct a three-day joint teaching activities of small design. Taking "Pavilion" as the subject, Professor Gu Daqing trained students to design quickly according to the given design conditions within specified time. The Chinese University of Hong Kong and the teachers of the University of Technology jointly participated in the training, and the learning content covered the training of space definition, the training of employing connection mode as a sort of formal language, the training of the structure and service space, and the training of the relationship between the site and the building. The students extensively applied the basic methods of architectural design in training, thus exercising the ability of the unification between hands and eyes, deepening the understanding of perspective, and completing the intensive training of model shooting. Moreover, it arouses students' interest in participating in academic activities, and it is regarded as a very meaningful and rewarding attempt.

Activity three: "Scientific Research Navigation". In this activity, teachers from the scientific research department of the school carried out relevant policy interpretation for the declaration of fund project, shared the writing skills of the application for the fund project, made analysis on the key points for the declaration of the achievement award of social science, and encouraged their students to participate actively in it. Teachers of other academic departments who had achieved good results in the declaration of scientific research funds were invited to share and exchange their experience in our institute. The teachers who had obtained national scientific research fund in our institute also organized a symposium on the exchange of minds to create a good academic atmosphere for the upcoming international, provincial and ministerial scientific research fund projects.

\section{The Methods OF ORGANIZING InStRUCTIONS}

\section{A. To Innovate the Activity through Inspirational Thoughts}

As in Fig. 7, in the beginning of the term, the school stimulated teachers to arrange the event in an enthusiastic manner, based on which the detailed scheme of the event was publicized together with the billboard presenting all academic activities. Apart from the academic seminars presided by teachers, the event arranged a special session concerning students' academic activities, in which seven students who was in charge of fund programs presented their mid-term reports and experienced teachers were nominated to give their opinions, so as to urge students to complete their programs on time, with required quantity and quality, and to enhance students' enthusiasm and interests to participate in academic activities. This session has been the highlight in the activity, boosting great innovation.

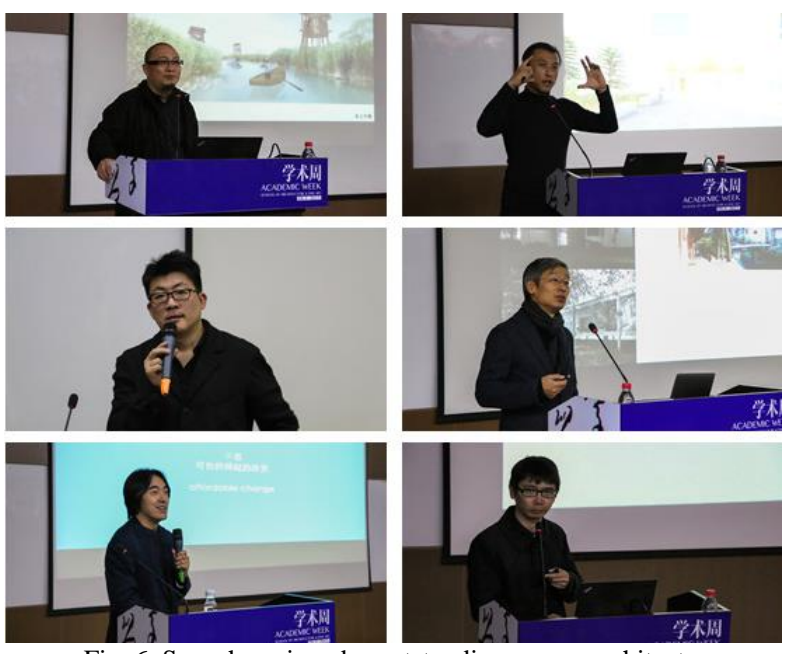

Fig. 6. Speeches given by outstanding young architects.

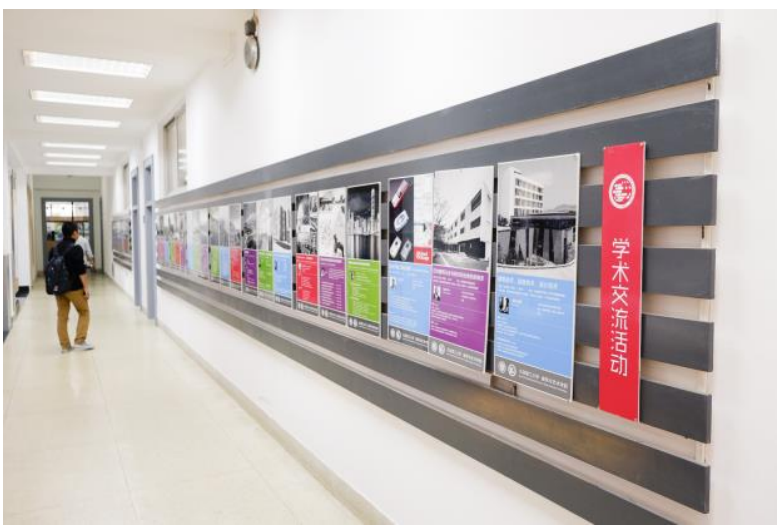

Fig. 7. Posters of academic week

\section{B. To Maintain the Order of the Event in a Considerate Manner}

In order to sustain the order of the Academic Week, to ensure its effectiveness, to maintain teachers' enthusiasm to participate in academic and educational activities and to 
respect the efforts of experts and professionals outside the university, the school arranged a joint conference between the Party and the government, in which the Associate Dean was identified to lead the event, the Departments of School and Teaching Affairs were required to coordinate and corporate and the Office of Students' Affairs was responsible to nominate people in charge of attendance, thereby recording students' participation in details. The Office of Teaching Affairs was required to arrange various academic activities and ensure the presence of relevant teachers and experts from outside. (see Fig. 8 and Fig. 9)

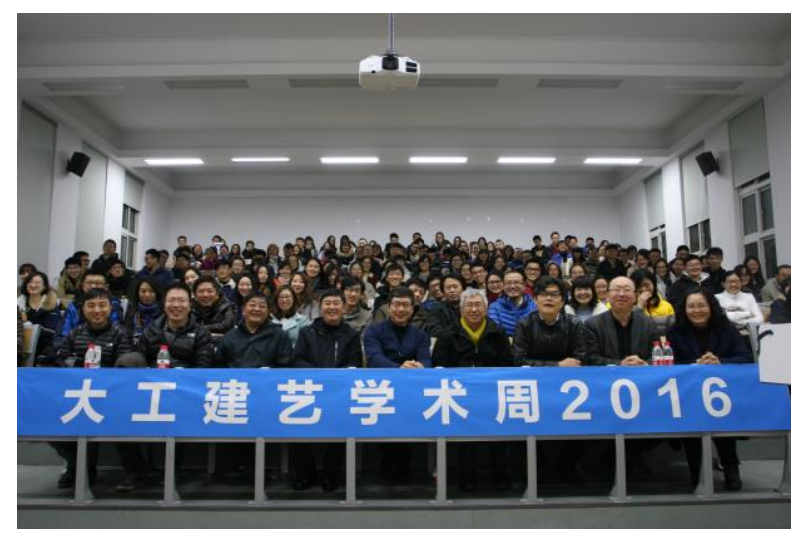

Fig. 8. Academic week in 2016.

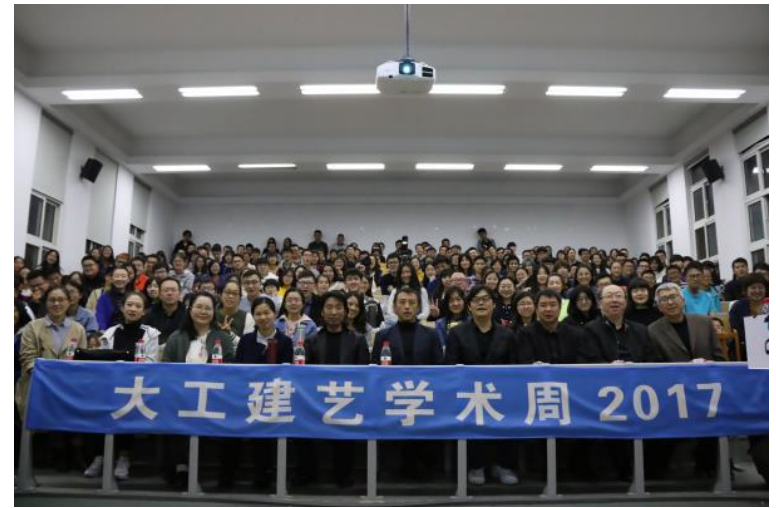

Fig. 9. Academic week in 2017.

\section{To Enhance Academic Awareness with Carefulness}

A notebook has been given out to students to record the event. They were required to write down the content of each activity, with their experiences, feelings and suggestions [8]. At the end of the event, the School launched a session to elect those who were positive and enthusiastic during the week, thereby praising their active participation.

\section{To Ensure the Scale of the Event through Various Channels}

The School set eight teachers to preside the academic seminars during the event, with multiple outside experts and professionals presenting their academic reports and instructions regarding learning and researches. The Heads of all Teaching and Research Offices, the professors of all majors and some key teachers participated in the activity to communicate their learning and researching knowledge with students, answering the questions, in presence, about researches, academic competitions, professional awareness, way to pursue a master degree and hunting jobs, which draw immense popularity from students. The seminars given by outside experts were designed for teachers and postgraduates, regarding the publication of their academic achievements, the extension of undergraduates' room to do business, etc. All these event reaped substantial praises.

\section{EXISTING PROBLEMS AND REFLECTIONS}

\section{A. The Lack of Awareness about the Significance of Academic Lectures}

Awareness is the prerequisite of behaviors. Academic lectures can significantly enhance academic communication, and guide students' learning and growth [9].

The root of the disparities between key universities and ordinary ones is the cultural environment existing in the campuses. Academic lectures, with targeted cultural contents and large attendance, play a crucial role in the learning and development of all teachers and students. The attraction and value of lectures are from their traditionally cultural contents and the crystallization of wisdom, which can easily be ignored. Hence, numerous universities are blind to the importance of academic lectures.

Academic lectures offer vim and vigor to universities and support their design of disciplines, serving as a basic form of academic development, as well as a new growth point of their majors and subjects [10]. Provided that the cultural value of lectures is neglected, their scientific and reasonable arrangement would not be ensured, let alone relevant premiums. Teaching, ground and financial resources are required to arrange lectures. Nevertheless, at present, universities are lack of funds, resulting in the lack of investment in launching academic lectures. Moreover, funds are needed to invite professionals, places and equipment. The absence of all above-mentioned elements would impact students' effectiveness to receive information, and inevitable wastes in this regard.

\section{B. The Lack of Interests among Seniors}

The majority of seniors did not possess enough time or interests to participate in the event, or even considered it as a week to rest and to arrange their own business, due to their great pressure dealing with multiple certificate tests, e.g. professional qualification certificates, postgraduate entrance examination and civil service examination. The influence of the Academic Week was rather small in regard to these senior students.

\section{The Inadequacy of the Channels and Openness of Resource-Sharing Platforms}

It is a shared responsibility of universities to meet the demands of teachers and students, and to achieve effective resource sharing. In order to enhance the exchanges and communication of superior academic lectures, the platform specially designed for exchanging resources of academic seminars was launched by 28 universities in the year of 2008 , which has set up independent web pages and managing platforms for individual university, so as to help publicize and manage relevant resources, and to achieve the interchanges and interactions in this regard. Nevertheless, the platform, with its member being 21, cannot fulfill the demands of over 2000 universities at the present moment, 
thereby proving its insufficient openness, as well as inadequate channels to share quality lectures.

\section{The Methods to Improve the Status Quo}

\section{A. To Change the Existing Mindset and to Deepen Our} Understanding - Including the Academic Week into Talent Training Programs

The major task of the Academic Week is to arrange a variety of academic lectures, which can further academic sharing and cultivate the academic environment in the campus. Universities, the crucial base to inherit traditional culture, to innovate existing theories and to cultivate talented personnel, require strong academic foundation and environment to from their vim and vigor. The academic ambience, one the one hand, can be discerned from the participation of teachers and students into research programs, and on the other hand, it can be seen from the degree of academic exchanges, frequency and quality of academic lectures and seminars.

Cultivating a top-class academic ambience is required to build world-class elites and universities. The Academic Week launched a series of lectures within a short period of time, with its inclusiveness to draw on successful experience of experts, thereby enabling students to widen their horizons, transcending over the limitation of disciplines, and enhancing their research abilities. Academic lectures, in which experts and scholars share their academic reports and viewpoints from immense efforts, provides audiences with advanced and the newest theories, academic viewpoints and development. Hence, academic lectures help improve the exchanges of expertise, expand the horizon, cultivate an atmosphere to inspire students to think critically, stimulate them to cope with issues in a considerate and multidisciplinary manner, and attain the width of liberal education and the depth of professional education. Fudan University and Shanghai Normal University have included academic lectures into their strategies to cultivate talented personnel, and initiated detailed rules regarding the management and application of lectures, thereby enhancing their effectiveness and ensuring the quality of academic activities, which is worthy of being studied and imitated in the following Academic Weeks.

The Academic Week not only stimulates students to improve their learning and professional advancement, but guides teachers to promote their skills and speciality. Teachers are encouraged to preside over the lectures of various themes, so as to improve their innovative competent transcending over the limitation of single discipline and to improve their academic levels through the interactions with professionals. Meanwhile, teachers' participation into the activity will improve students' initiative in this regard, thereby fostering a virtuous ambience in which both teachers and students can benefit, thus achieving long-range academic development.

B. To Initiate Integrated Plans and Enhance Influence Improving the Participation of the Event in a Professional Manner

Currently, the Academic Weeks held by most universities are not systematic and well-planned. The activities are not arranged in an orderly manner with the amount and themes of lectures poorly designed. Some universities even launch temporary activities merely during the week. In order to fulfill the positive function of the Academic Week, and to reach its authentic value, universities are required to enhance their awareness in this regard, to strategically arrange the activity, to intensify the promotion, to draw a detailed plan and arrangements regarding activities, lectures and management. Sufficient investment is required to initiate quality academic activities, invite domestic and foreign experts and scholars, and to provide appropriate venues and equipment. However, due to the limited funding and the lack of awareness regarding the significance of the Academic Week, numerous universities excessively cut down their budgets, therefore diminishing the quality of academic activities, and resulting in the poor quantity and quality of the event. Hence, universities are claimed to set up transparent and standard rules to manage the funding, and to include the expenditure of the Academic Week into the budget, in order to make good use of it.

It is needed to enhance the association between the Academic Week and social demands of various specialties, and to launch relevant academic activities connecting with students' majors, on the basis of the training and developmental orientation of undergraduates and postgraduates, as well as their career prospects. It is claimed to frequently invite the personnel from the corporate world and all statuses of society, and academic talents from other countries, to interact with teachers and students during the event, thereby enabling all faculties and students to arrange their individual studies and researches, according to the status quo and the development of their majors. Meanwhile, it is also demanded to invite experts of multiple majors, to effectively plan and arrange the event based on different needs of majors, and to consult relevant employers related to the university, thereby closely connecting the activity with social demands.

It is required to publicly arrange academic lectures, improve their quality, and enhance the interactions, so as to fulfill their functions of instruction and experience. It is important to strengthen the management of the lecture, foresee the diversified demands of teachers and students through a variety of methods, receive feedback and comments on time, supervise the quality of academic lectures, so as to ensure that the purpose of each lecture is met.

Last, the quality of the Academic Week can only be attained through considerate plans and arrangements. Modern media can be effectively utilized to seek an appropriate form to launch academic lectures. Additionally, more salons can be held to create a virtuous situation in which all ideas bloom together, and a beneficial and interactive ambience.

\section{To Share Resources and Achieve Mutual Benefits - Attaining Effective Use of Academic Resources}

The influence of the Academic Week should not be restricted in the campus, but let more individuals experience its charm and effectiveness. Advanced media resources should be exploited to publicize the arrangement and plan of 
the event, in order to let more people get relevant data and information, achieving effective use of resources. Numerous online tools, e.g. the official page of the university, students' website, BBS, the WeChat platform and other applications, can be used to attain information sharing. A column for activity arrangements could be set on the official website, to inform users about relevant activities ahead of schedule, and to offer information regarding time, venues, themes, guests, speakers and types, thereby increasing the influence of the event. Individuals could be appointed to update the information at regular intervals, then summarize and publicize the activity information of various departments, thus facilitating the process in which students and other users check and choose.

The organizers of lectures can forecast general contents before they start the event, to let participants fully note their growth and professional backgrounds, as well as their academic achievements. Apart from traditional posts, advanced applications, e.g. Microblog, WeChat and official apps can be applied in order to expand the way lectures get publicized, esp. the most commonly-used online app, WeChat. The publication and fast spread of academic activities can be attained by the official accounts and mini programs in WeChat.

During the process of planning the event, multiple ways, e.g. online votes, information gathering from Microblog, and surveys, can be utilized to know the preference of teachers and students regarding the types of activities and the figures in the academic field, thereby better preparing the following activities. Such methods can shorten the distance between the Academic Week and teachers and students, as well as improve their enthusiasm to participate in the event, and promote academic environment. After the academic lecture, various channels can be exploited to gather and analyze participants' feelings and comments, based on which the demands of teachers and students can be fully addressed.

To construct a platform sharing academic resources can attain the relevant exchanges among universities, thus promoting the utilization percentage of academic lectures and resources. With the advancement of online video-editing technology, the scene of academic activities can be stored and represented. Experts' diversified voices and inspiring discourses will enlighten students' mindset once again. After having set the mutual platform, students can search relevant academic resources from domestic and foreign universities through the Internet. In so doing, they can effectively use a variety of academic resources, to enhance their academic knowledge and to illumine their way to pursue truth.

\section{CONCLUSION}

As the saying goes, "the prosperity of a country relies on the vigor of the young, while the strength of a nation depends on the strong characters of the youngsters. Once the new generations obtain their own dreams, abilities, responsibilities, the whole country will attain immense prospect, and the whole nation will possess hope." The Reports of the 19th National Congress of the CPC, in essence, reiterates the sincere hope of the country towards the young generation. To realize the Chinese Dream to achieve the prosperity of the Chinese nation depends on talents and education. Quality higher education serves as an important engine to cultivate innovative personnel, to achieve national modernization and to revive the Chinese nation. Academic activities are a crucial part in fulfilling the function of higher education. Academic lectures, with its great flexibility and wide participation, will inevitably exert huge influence on students. The success of the Academic Week Held in the School of Architecture and Fine Art of Dalian University of Technology completely presents its instructional and research practices, and serves as a new experiment to enhance the academic ambience in the campus. Through various activities, e.g. salons and academic lectures, the academic feast was attained by experts and scholars from domestic and foreign areas, and from inside and outside the university. The event, with its wide channels and multiple perspectives, deeply attracted numerous students into the scientific banquet, greatly expanding the way academic activities were launched, widening the coverage, increasing the audiences from all walks of life, and enhancing the participation. Through this academic communication, which is at a higher starting point, wider sphere and multiple scopes, teachers and students have better noted the advanced development of the major by being inspired and numerous discussions. The School will continue to improve the event and exchanges in joint efforts, so as to expand their horizons, to construct a platform to share scientific information and exchanges at a higher level, and to endeavor to improve the research ability and development in great momentum.

\section{ACKNOWLEDGMENT}

Thanks are due to Professor Yue Fan and Shiyuan Wang for their instructive advice and useful suggestions on the thesis and to Jie Tao for valuable discussion. In addition, the authors wish to thank Graduate School of Dalian University of Technology for their special fund on graduate student affairs. This work was supported in part by their support.

\section{REFERENCES}

[1] H. Mann, Lectures on Education, 1st ed. Germany: Nabu Press, 2010, pp. $121-123$

[2] J. Jeon, "A study of listening comprehension of academic lectures within the construction-integration model," Academic Listening, vol. 17, pp. 54-59, Jan 2007.

[3] A. Thatcher, G. Mooney, and N. Israel et al., "Attendance and academic performance in psychology tertiary education lectures in South Africa," Teaching Psychology around the World, vol. 12, pp. 166-185, Jan 2009.

[4] M. R. Berkowitz, "Assessing impact of not attending lectures on osteopathic medical student performance: Brief survey of the literature and proposed future research," International Journal of Osteopathic Medicine, vol. 16, pp. 212-215, Dec 2013.

[5] S. E. Thompson, "Text-structuring metadiscourse, intonation and the signalling of organisation in academic lectures," Journal of English for Academic Purposes, vol. 2, pp. 5-20, Jan 2003

[6] I. Kageyama, K. Yoshimura, Y. Satoh, C. D. Nanayakkara, R.W Pallegama, and S. Iwasaki, "Proposal for research and education: Joint lectures and practicals on central nervous system anatomy and physiology," The Journal of Physiological Sciences, vol. 66, no. 4, pp. 283-292, Apr. 2016.

[7] R. J. Godfrey, "The provision of postgraduate taught lectures and seminars in support of $\mathrm{PhD}$ education at Brunel University: Student perception and alignment with official academic guidelines," Journal of Hospitality, Leisure, Sports and Tourism Education, vol. 2, p. 54, Feb. 2005. 
[8] F. Ollermann, R. Rolf, C. Greweling, and A. Klaßen, "Principles of successful implementation of lecture recordings in higher education," Interactive Technology and Smart Education, vol. 1, pp. 2-13, Jan. 2017.

[9] E. Weymuller, "The 2004 Ogura lecture: Matching graduate education with societal need," The Laryngoscope, vol. 2, pp. 218-222, Feb. 2005.

[10] A. Rahman, M. A. R. Shah, and S. H. Chowdhury, "Lecture capture use in engineering education: Influence of students' social and behavioral factors and teachers' perceptions," Computer Applications in Engineering Education, vol. 8, pp. 500-508, Feb. 2018.

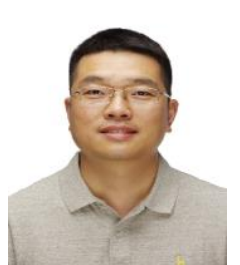

Dongyang Wang received his bachelor from Dalian University of Technology, China in 2007; He received his MSc degree from Dalian University of Technology, China in 2012. He is principal investigator of one graduate project funded by Dalian University of Technology. He is a graduate counsellor, secretary of administrative office party branch of CPC Committee of School of Architecture and Fine Art, Dalian University of Technology, Dalian, China.

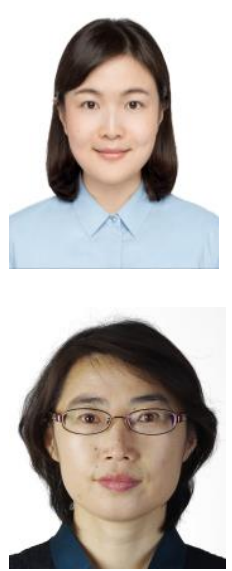

Yan Xiao received her bachelor of urban planning from Dalian University of Technology, China in 2009. She received her MSc degree from Dalian University of Technology, China in 2012 and PhD in architectural design and theory at Dalian University of Technology, China in 2015. She is a lecturer at School of Architecture and Fine Art, Dalian University of Technology, Dalian, China.

Jie Tao received her bachelor of English language and literature from Dalian University of Foreign Languages, China in 1993. She is the assistant dean and deputy secretary of CPC Committee of School of Architecture and Fine Art, Dalian University of Technology, Dalian, China. 